\title{
BEYOND CORTICOSTEROIDS: RISK FACTORS FOR AVASCULAR BONE NECROSIS IN PATIENTS WITH SYSTEMIC LUPUS ERYTHEMATOSUS
}

Larissa de Barros Oliveira (Hospital Federal dos Servidores do Estado, Rio de Janeiro, RJ, Brasil), Adib Chicre Mansur Neto (Hospital Federal dos Servidores do Estado, Rio de Janeiro, RJ, Brasil), Mauro Goldfarb (Hospital Federal dos Servidores do Estado, Rio de Janeiro, RJ, Brasil), Marilena Leal Mesquita Silvestre Fernandes (Hospital Federal dos Servidores do Estado, Rio de Janeiro, RJ, Brasil), Adriana Danowski (Hospital Federal dos Servidores do Estado, Rio de Janeiro, RJ, Brasil)

\section{BACKGROUND}

Avascular necrosis (AVN) causes serious physical disability in patients with systemic lupus erythematosus (SLE). The aims of this study were to describe the prevalence and identity the predictive factors associated with symptomatic AVN in a SLE cohort.

\section{MATERIALS AND METHODS}

At the Lupus Clinic patients (ACR classification criteria) have been followed prospectively. AVN was recorded if patients were symptomatic and confirmed by imaging studies. To determine the prevalence and AVN predictors, a cross section design was performed. Demographics, clinical, laboratory and therapeutic variables were included as predictors. Univariate analysis were carried out on each potential

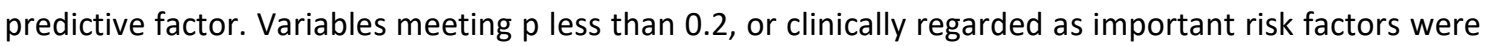
selected for multivariable regression analysis.

\section{RESULTS}

Among of 604 SLE patients registered in our database (93,9\% female, mean age 50 years), $20(3,4 \%)$ developed symptomatic AVN. Univariate analysis identified nephrotic syndrome $(p=0,007, \mathrm{OR} 3,75 ; \mathrm{Cl}$ : $1,34-10,48)$, proteinuria ( $p=0,001$, OR 4,75, Cl: $1,68-13,39)$, seizure $(p=0,022$, OR 3,51;Cl: $1,11-11,04)$, corticosteroid dose greater than $20 \mathrm{mg}(\mathrm{p}=0,033$, OR 3,55; $\mathrm{Cl}: 1,02-12,26)$ and greater than $30 \mathrm{mg}$ ( $p=0,041$, OR 4,12; $\mathrm{Cl}: 0,94$ - 17,97), IV methylprednisolone ( $p=0,011$, OR 3,09; $\mathrm{Cl}: 1,24-7,68$ ), methotrexate in the past $(p<0,01$, OR 4,62; $C l: 1,87-11,42)$ and azathioprine in the past $(p=0,010,0 R 4,9$; $\mathrm{Cl}: 1,85-12,96)$, anti-SM ( $p=0,031$, OR 2,65; $\mathrm{Cl}: 1,05-6,65)$ as statistically significant. We selected other variables with $\mathrm{p}$ value $<0,20$ in univariate analysis to include in the model: cyclophosphamide in the past, psychosis and chronic kidney disease. Methotrexate in the past ( $p=0,001, \mathrm{OR} 6,54 ; \mathrm{Cl}: 2,10-20,38)$, azathioprine in the past ( $p=0,026$, OR 4,37; $\mathrm{Cl}: 1,19-15,97)$ and nephrotic syndrome $(p=0,048,0 R 4,39$; $\mathrm{Cl}: 1,01-19,11)$ remained as the primary predictors associated with AVN on multivariable analysis.

\section{CONCLUSION}

Our findings demonstrated that severe clinical manifestations of SLE were associated with the presence of AVN, probably linked to the amount of the corticosteroids required. Azathioprine and methotrexate came out as variables related with this condition. At this point, it's not clear if that's something related with the drug itself or the requirement for additional corticosteroids associated with these immunosuppressants. 